Supporting Information

\title{
Preparation of Non-precious Metal Electrocatalysts for the Reduction of Oxygen Using a Low-Temperature Sacrificial Metal
}

\author{
Talha Al-Zoubi, ${ }^{\dagger}$ Yu Zhou, ${ }^{\dagger}$ Xi Yin, ${ }^{\prime}$ Blanka Janicek, ${ }^{\ddagger}$ Chengjun Sun, ${ }^{*}$ Charles E. Schulz,,${ }^{\S}$ \\ Xiaohui Zhang, ${ }^{\circledR}$ Andrew A. Gewirth, ${ }^{\perp}$ Pinshane Huang, ${ }^{\ddagger}$ Piotr Zelenay, ${ }^{\prime}$ and Hong Yang ${ }^{*,+,}$
}

${ }^{\dagger}$ Department of Chemical and Biomolecular Engineering, University of Illinois at UrbanaChampaign, 600 S. Mathews Avenue, Urbana, Illinois 61801, United States

\| Materials Physics and Applications Division, Los Alamos National Laboratory, Los Alamos, New Mexico 87544, United States

* Department of Materials Science and Engineering, University of Illinois at Urbana-Champaign, 1304 W. Green Street, Urbana, Illinois 61801, United States

* X-ray Science Division, Argonne National Laboratory, 9700 South Cass Avenue, Argonne, Illinois 60439, United States

$\S$ Department of Physics, Knox College, 2 East South Street Galesburg, Illinois 61401, United States

" CRRC Industrial Academy Co., Ltd, F9, Building 5, Noble Center II, East Qichebowuguan Road, Fengtai, Beijing 100070, P. R. China

${ }^{\perp}$ Department of Chemistry, University of Illinois at Urbana-Champaign, 505 S. Mathews Avenue, Urbana, Illinois 61801, United States

$\S$ Department of Physics, Knox College, 2 East South Street Galesburg, Illinois 61401, United States

*Correspondence to: Hong Yang (hy66@illinois.edu) 
Chemicals and Reagents. Cadmium nitrate tetrahydrate $\left(\mathrm{Cd}\left(\mathrm{NO}_{3}\right)_{2} \cdot 4 \mathrm{H}_{2} \mathrm{O}\right)$ (Alfa Aesar, $\geq 98.5 \%$ ), iron nitrate nonahydrate $\left(\mathrm{Fe}\left(\mathrm{NO}_{3}\right)_{3} \cdot 9 \mathrm{H}_{2} \mathrm{O}\right) \quad$ (Sigma Aldrich, $\geq 98 \%$ ), 1,4diazabicyclo[2.2.2] octane (DABCO) (Sigma Aldrich, $\geq 99 \%$ ), dimethylformamide (DMF) (Fisher Chemical, 99.9\%), terephthalic acid (TPA) (Alfa Aesar, 98+\%), 1, 10-phenanthroline (Sigma Aldrich, $\geq 99 \%$ ), ammonia $\left(\mathrm{NH}_{3}\right)$ (Airgas Inc., anhydrous 99.99\%)

Synthesis. In a typical procedure, the dual-ligated Cd-Fe-DABCO-TPA metal-organic frameworks (MOFs) were made from a mixture of $\mathrm{Cd}\left(\mathrm{NO}_{3}\right)_{2} \cdot 4 \mathrm{H}_{2} \mathrm{O}(498 \mathrm{mg}), \mathrm{Fe}\left(\mathrm{NO}_{3}\right)_{3} \cdot 9 \mathrm{H}_{2} \mathrm{O}(8.2$ $\mathrm{mg}$ ) and DABCO (548.2 mg) in $15 \mathrm{~mL}$ of DMF. The above mixture reacted in a $50 \mathrm{~mL}$ three-neck flask at $150^{\circ} \mathrm{C}$ using a magnetic stirrer/hot plate (VWR, Cat. No. 97042-714). In a separate beaker, TPA (803.4 mg) was completely dissolved in $10 \mathrm{~mL}$ of DMF at $150{ }^{\circ} \mathrm{C}$ before being poured into the above three-neck flask. An additional $10 \mathrm{~mL}$ of DMF was added subsequently into the beaker and then transferred into the three-neck flask to bring the total volume of the mixture to $\sim 35 \mathrm{~mL}$. This flask was placed in a home-made aluminum heating block preheated to $150{ }^{\circ} \mathrm{C}$ using a magnetic stirrer/hot plate and connected to a condenser. The reaction was carried out for $2 \mathrm{~h}$ at this temperature and a stirring rate of $400 \mathrm{rpm}$. After the reaction, the condenser was removed to allow for the evaporation of DMF in $12 \mathrm{~h}$. The resulting MOF product was collected and washed with a total of $65 \mathrm{~mL}$ of hot $\mathrm{DMF}\left(\sim 150{ }^{\circ} \mathrm{C}\right)$ for three times, followed by centrifuging at $9000 \mathrm{rpm}$ (Beckman Coulter Inc., Allegra X-30 Series) until a clear supernatant was obtained. The product was then dried at $80^{\circ} \mathrm{C}$ under vacuum overnight to obtain the final MOF product.

To synthesize the non-PGM Fe-C-N electrocatalyst, the as-made Cd-Fe-DABCO-TPA MOF precursor $(600 \mathrm{mg})$ and 1, 10-phenanthroline $(150 \mathrm{mg})$ were ball-milled for $2 \mathrm{~h}$ in a rotary ball mill (Fritsch Planetary Micro-Mill, Pulverisette 7") using a 12-mL crucible equipped with five 12$\mathrm{mm}$ agate balls of the same material. The ground powder was collected and transferred to an 
alumina boat (Sigma Aldrich, $5 \mathrm{~mL}$ ). This combustion boat was then placed inside of a quartz tube (I.D.: $22 \mathrm{~mm}$, O.D.: $25 \mathrm{~mm}$, and length: $0.6 \mathrm{~m}$ ), and purged with $\mathrm{NH}_{3}$ for about $95 \mathrm{~min}$. After the purge, the tube was inserted into a tube furnace (Thermo Fisher Scientific ${ }^{\mathrm{TM}}$, Lindberg/Blue $\mathrm{M}^{\mathrm{TM}}$ Mini-Mite ${ }^{\mathrm{TM}}$ ) that was preheated to either $750{ }^{\circ} \mathrm{C}$ or $950{ }^{\circ} \mathrm{C}$, and kept at this temperature for 15 min. After the reaction, the quartz tube was removed from the furnace and allowed to cool to room temperature under the flow of $\mathrm{NH}_{3}$. The final product was collected and grounded using a mortar and pestle to obtain the final catalyst.

Materials Characterization. Scanning electron microscopy (SEM) images were obtained using a Hitachi S4700 at an acceleration voltage of $10 \mathrm{kV}$. SEM specimen were prepared by directly placing catalysts onto carbon tape on a sample holder. Transmission electron microscopy (TEM) micrographs were obtained using a JEOL 2100 Cryo TEM with an accelerating voltage of $200 \mathrm{kV}$. TEM samples were prepared by depositing a drop of dispersion of catalysts in ethanol on carbon coated TEM grids. Powder x-ray diffraction (PXRD) patterns were obtained using a Rigaku Miniflex 600 with a $\mathrm{Cu} K_{\alpha}$ radiation. Typically, a continuous scan was performed between 10 and $80^{\circ} 2 \theta$. Scanning transmission electron microscopy (STEM) images and electron energy dispersive loss spectroscopy (EELS) were obtained using a Thermo Fisher Scientific Themis Z advanced probe aberration corrected analytical TEM/STEM at an accelerating voltage of $80 \mathrm{kV}$. Images were acquired in a monochromated STEM mode with a $1.2 \AA$ probe size, $0.3 \mathrm{eV}$ energy spread, $30 \mathrm{mrad}$ convergence angle, and approximately 20 pA probe current. The ADF-STEM image is lightly smoothed to decrease noise. EELS spectra were acquired on a Gatan imaging filter (GIF Quantum 965) with $0.25 \mathrm{eV}$ dispersion and $25 \mathrm{mrad}$ collection angle. The EEL spectrum was acquired by continuously scanning the electron beam over an area similar to the ADF-STEM image and summing multiple EEL spectra. Each spectrum was acquired at a 0.2 -s dwell and a total 
of 1400 frames were summed up to obtain the final EEL spectrum. For the inset Fe- $\mathrm{L}_{2,3}$ edge, a power-law background subtraction was performed in Matlab and a Savitksy-Golay filter was applied to increase the signal to noise ratio. Samples were prepared using the same method outlined for the TEM samples above. Inductively coupled plasma mass spectroscopy (ICP-MS) analysis was carried out on a PerkinElmer NexION 350D system. Brunauer-Emmett-Teller (BET) surface area analysis was performed using a Micromeritics 3Flex Analyzer and SmartVac Degasser. X-ray absorption spectroscopy (XAS) was performed in transmission mode using beamline 20-BM-B at the Advanced Photon Source (APS) at Argonne National Laboratory. Sample pellets were prepared by pressing $\sim 20 \mathrm{mg}$ of the catalyst and an equal amount of boron nitride powders using a benchtop manual press and $6 \mathrm{~mm}$ pellet die (Carver, Inc). The obtained XAS data were analyzed using the Athena software. Mössbauer analysis was performed with a $\mathrm{Co}^{57}$ source emitting gamma rays at $14.4 \mathrm{keV}$ on a constant acceleration spectrometer at $300 \mathrm{~K}$. Xray photoelectron spectroscopy (XPS) was performed using a Kratos Axis ULTRA with an Al $K_{\alpha}$ monochromatic x-ray source to determine the binding energy values of nitrogen in each of the catalyst samples.

Electrochemical Measurements. A three-electrode setup was used to evaluate the oxygen reduction reaction (ORR) performance of these catalysts. Graphite rod (Pine, MPGRR250) was used as the counter electrode and a reversible hydrogen electrode (Hydroflex ${ }^{\mathrm{TM}}$, ET070 eDAQ) was used as the reference. The working electrode was prepared by the following procedure: an ink containing $235 \mu \mathrm{L}$ of deionized (DI) water $\left(18.2 \mathrm{MW} \cdot \mathrm{cm}\right.$, Thermo Fisher Scientific ${ }^{\mathrm{TM}}$, Barnstead $^{\mathrm{TM}}$ E-Pure ${ }^{\mathrm{TM}}$ ), $235 \mu \mathrm{L}$ of ethanol (200 Proof, Decon Labs, Inc.), and $45 \mu \mathrm{L}$ of Nafion binder (D521 alcohol based $1100 \mathrm{EW}$ at 5\% weight, Nafion ${ }^{\mathrm{TM}}$ Store) were mixed with $5 \mathrm{mg}$ of the catalyst. This ink mixture was sonicated for $30 \mathrm{~min}$ prior to drop-casting onto the surface of a 
glassy-carbon rotating disk electrode (RDE). A total of $20 \mu \mathrm{L}$ of the ink was deposited onto the surface of RDE in two equal portions. After the first deposition of $10 \mu \mathrm{L}$, the ink was dried for 10 min, followed by depositing another $10 \mu \mathrm{L}$ to generate a thin film catalyst layer on the electrode surface. The ORR performance of the catalysts was tested in $0.1 \mathrm{M}$ perchloric acid $\left(\mathrm{HClO}_{4}\right)$ electrolyte (70\% Veritas Double Distilled, GFS Chemicals) using a standard three-electrode system. Oxygen gas (Airgas Inc., 99.999\%) was bubbled through the electrolyte for a total of 40 min prior to the RDE testing. Prior to the measurements, the catalysts underwent a conditioning step in situ by sweeping between $0 \mathrm{~V}$ and $1.1 \mathrm{~V}$ at a step of $0.01 \mathrm{~V}$ for two times using linearsweep voltammetry (LSV). Staircase voltammetry (SCV) was carried out between $0.0 \mathrm{~V}$ and 1.1 $\mathrm{V}$ at an interval of $0.02 \mathrm{~V}$ and a measurement time of $30 \mathrm{~s}$ to obtain the polarization curves.

Membrane Electrode Assembly (MEA) Testing. The MEAs were fabricated using a method reported elsewhere. ${ }^{1}$ The catalyst inks were prepared by sonicating a mixture of catalyst, ionomer dispersion (Aquivion ${ }^{\circledR}$ D83-24B, EW $830 \mathrm{~g} / \mathrm{mol} \mathrm{SO}_{3} \mathrm{H}$, Sigma-Aldrich), DI-water and isopropanol (Fisher Chemical, $>99.5 \%$ ) in an ultrasonic bath for $3 \mathrm{~h}$. The $5 \mathrm{~cm}^{2}$ MEA was fabricated by first hot-pressing a Pt anode (gas diffusion electrode, $40 \% \mathrm{Pt}$ on Vulcan ${ }^{\circledR}$ carbon, $0.3 \mathrm{mgt}_{\mathrm{Pt}} \mathrm{cm}^{-2}$, Sigracet ${ }^{\circledR} 29$ BC carbon fiber paper) to one side of a Nafion ${ }^{\circledR}$ NR-211 membrane at a temperature of $120{ }^{\circ} \mathrm{C}$ and a pressure of $5.3 \mathrm{MPa}$ for $5 \mathrm{~min}$. The catalyst ink was then brush-painted to the cathode side of the membrane at $\sim 80^{\circ} \mathrm{C}$ to achieve predetermined catalyst loadings of ca. 4.8 or $6.8 \mathrm{mg} \mathrm{cm}^{-2}$. The full MEA was assembled with a gas diffusion layer (GDL, Sigracet ${ }^{\circledR} 29 \mathrm{BC}$ carbon fiber paper) covering the cathode catalyst layer. Two PTFE gaskets were used for sealing the MEA in the cell hardware at ca. $75 \%$ to $80 \%$ of its original thickness. The $\mathrm{H}_{2} / \mathrm{O}_{2}$ fuel cell performance was measured at $80^{\circ} \mathrm{C}$, using fully humidified gases. The partial pressure of $\mathrm{H}_{2}$ at the anode and the partial pressure of $\mathrm{O}_{2}$ at the cathode was maintained at 1.0 bar. The flow rate of 
$\mathrm{H}_{2}$ was set at $200 \mathrm{sccm}$. For the MEA with catalyst loading of $4.8 \mathrm{mg} \mathrm{cm}^{-2}$ and $35 \mathrm{wt} . \%$ of D83 ionomer, the flow rate of $\mathrm{O}_{2}$ was $500 \mathrm{sccm}$. For the MEA with catalyst loading of $6.8 \mathrm{mg} \mathrm{cm}^{-2}$ and $45 \mathrm{wt} . \%$ of $\mathrm{D} 83$ ionomer, the flow rate of $\mathrm{O}_{2}$ was $200 \mathrm{sccm}$. The polarization plots were recorded from an open cell voltage (OCV, ca. $0.96 \mathrm{~V})$ to $0.2 \mathrm{~V}$ at steps of $0.02 \mathrm{~V}$ with a step period of $10 \mathrm{~s}$. 


\section{Figures}

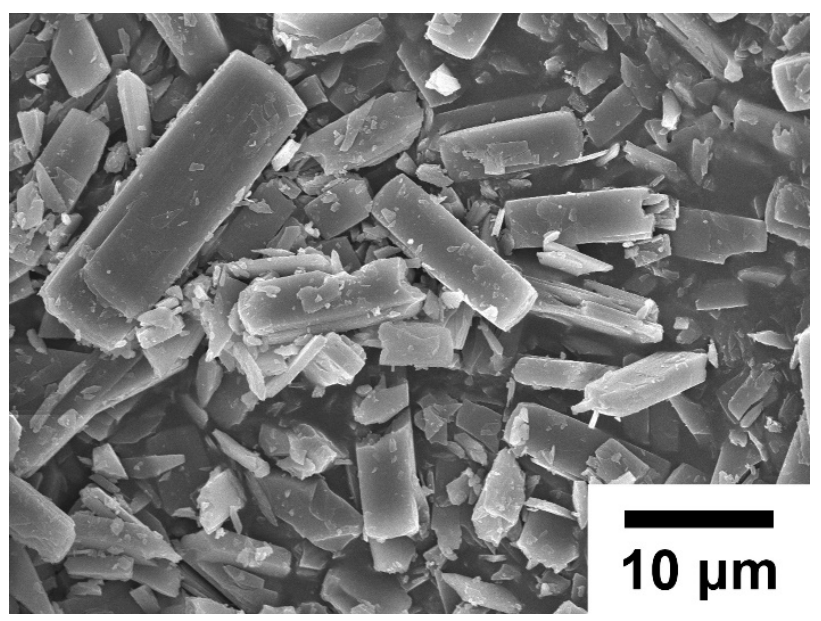

Figure S1. Representative SEM image of as-made Cd-DABCO-TPA MOF (without Fe) crystals, showing the overall morphology is similar to that of Cd-Fe-DABCO-TPA MOF. 


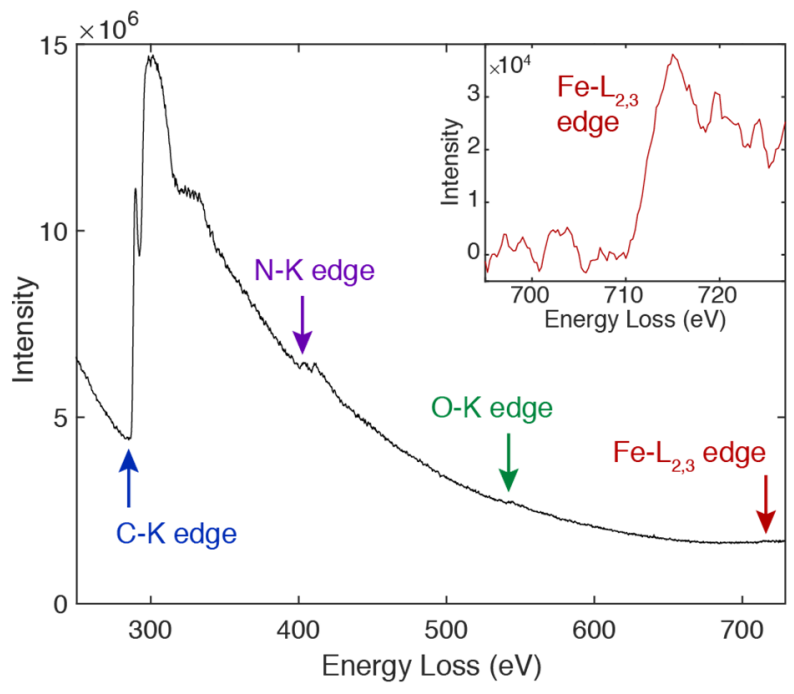

Figure S2. EEL spectrum showing the presence of C, N, O, and Fe. (inset) Background subtracted spectrum of Fe-L2,3 edge. The inset spectrum was smoothed using a Savitsky-Golay filter to improve the signal to noise ratio. 

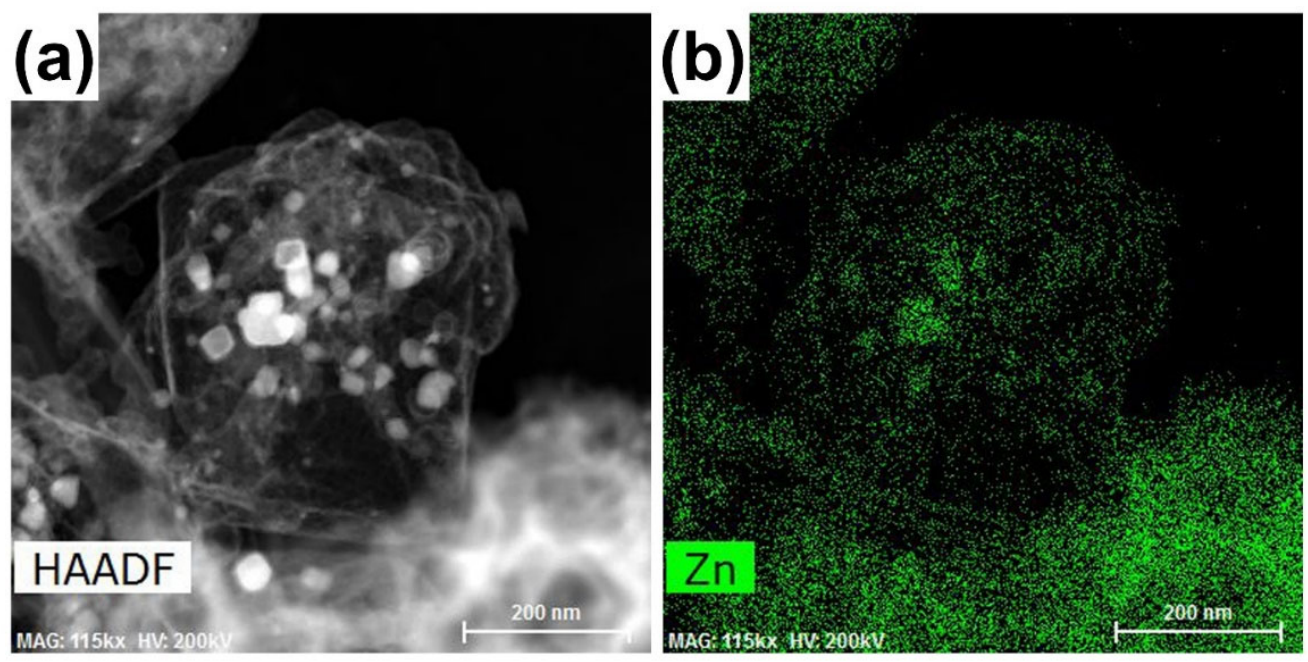

Figure S3. (a) Representative TEM image of as-made $\mathrm{ZIF}-8 / \mathrm{Fe}_{750}$, showing the presence of nanoparticles encapsulated by carbon, and (b) EDS mapping exhibiting the large-area distribution of $\mathrm{Zn}$ in the catalyst after pyrolysis. 


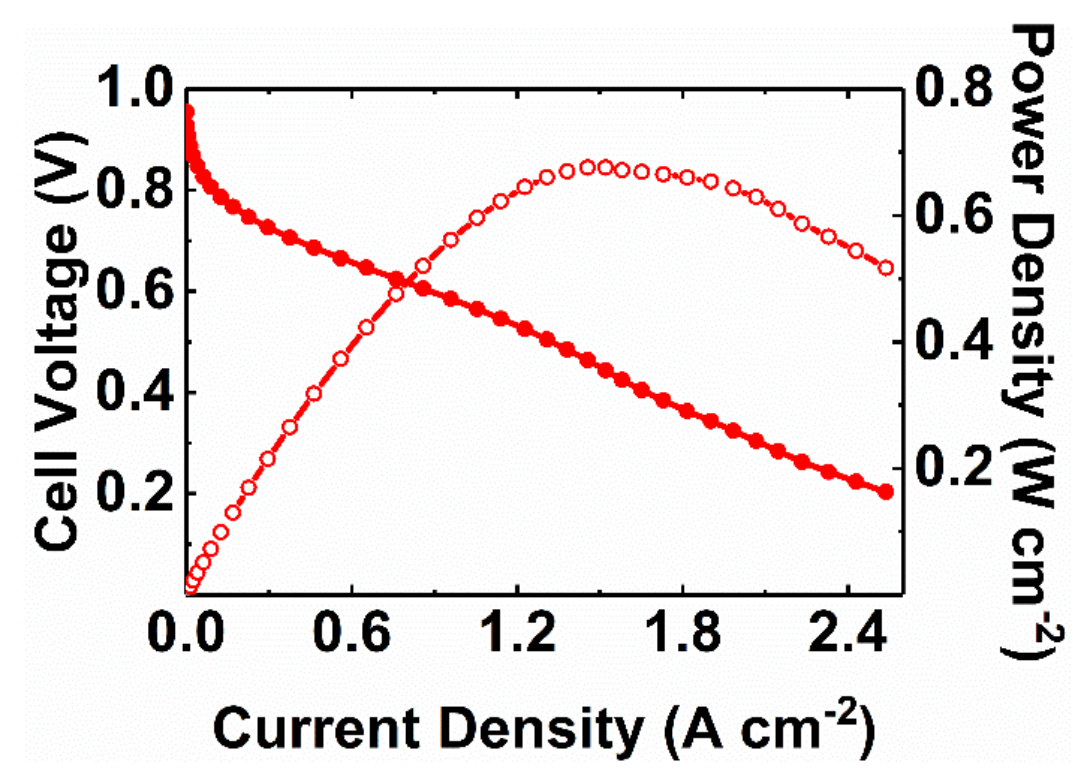

Figure S4. Single cell performance of MEA made of Fe-C-N950 non-PGM ORR electrocatalyst under the $\mathrm{H}_{2} / \mathrm{O}_{2}$ testing conditions. Cathode: Fe-C-N950 catalyst, ca. $4.8 \mathrm{mg} \mathrm{cm}^{-2}, 35$ wt.\% D83 ionomer, 1.0 bar $\mathrm{O}_{2}$ partial pressure, $500 \mathrm{sccm}, 100 \% \mathrm{RH}$; Anode: $40 \mathrm{wt} \% \mathrm{Pt} / \mathrm{C}, 0.3 \mathrm{mgt}_{\mathrm{Pt}} \mathrm{cm}^{-2}, 1.0$ bar $\mathrm{H}_{2}$ partial pressure, $200 \mathrm{sccm}$; Cell: $80{ }^{\circ} \mathrm{C}, 100 \% \mathrm{RH}$, Nafion NR-211 membrane. 


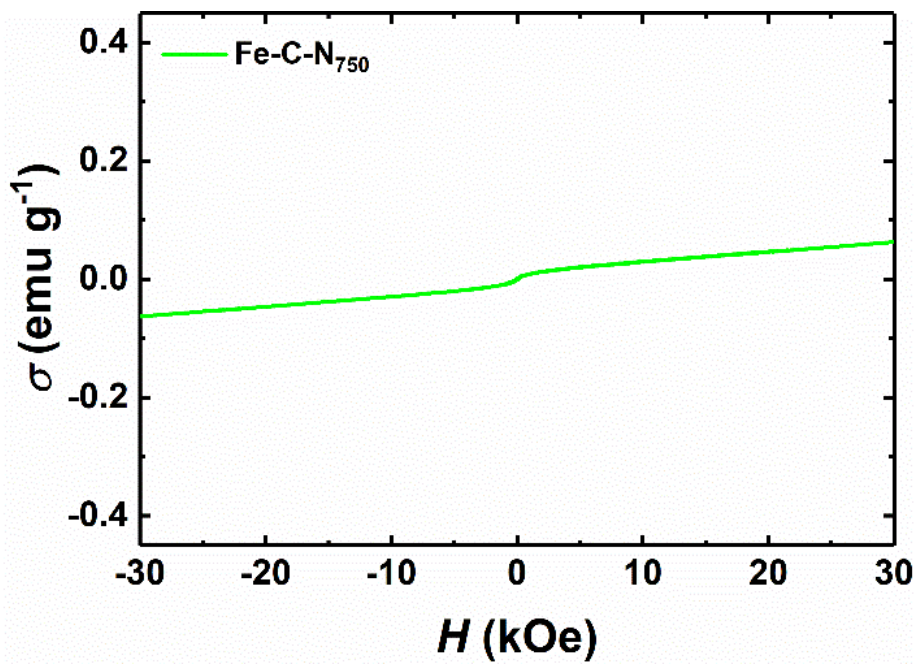

Figure S5. Vibrating-sample magnetometry (VSM) analysis of the Fe-C-N750 catalyst showing no magnetic hysteresis, an indication of the lack of ferromagnetic species. 
Table S1. Mossbauer spectroscopy results for the Fe-C-N 750 electrocatalyst

\begin{tabular}{|c|c|c|c|c|c|c|}
\hline Component & $\begin{array}{c}\boldsymbol{\delta}_{\text {iso }} \\
\left(\mathbf{m m ~ s}^{-1}\right)\end{array}$ & $\begin{array}{c}\Delta \mathbf{E}_{\mathbf{Q}} \\
\left(\mathbf{m m ~ s}^{-1}\right)\end{array}$ & $\begin{array}{c}\text { FWHM } \\
\left(\mathbf{m m ~ s}^{-1}\right)\end{array}$ & $\begin{array}{c}\text { Absorbance } \\
(\mathbf{\%})\end{array}$ & Assignment & Ref. \\
\hline Doublet 1 & 0.43 & 1.37 & 1.38 & 27.3 & $\mathrm{FeN}_{4}$ & 2 \\
\hline Doublet 2 & 0.16 & 0.35 & 0.48 & 72.7 & $\begin{array}{c}\mathrm{Fe}_{\mathrm{x}} \mathrm{N}(\mathrm{x}< \\
2.1)\end{array}$ & 3 \\
\hline
\end{tabular}

Table S2. X-ray photoelectron spectroscopy analysis of the nitrogen species in the Fe-C-N750 electrocatalyst

\begin{tabular}{|c|c|}
\hline Species & Binding Energy (eV) \\
\hline Pyridinic & 398.0 \\
\hline Fe-N & 399.2 \\
\hline Pyrrolic & $400.6-400.8$ \\
\hline Graphitic & 402.6 \\
\hline
\end{tabular}




\section{References}

1. Yin, X.; Lin, L.; Chung, H. T.; Komini Babu, S.; Martinez, U.; Purdy, G. M.; Zelenay, P., Effects of MEA fabrication and ionomer composition on fuel cell performance of PGM-free ORR catalyst. ECS Trans. 2017, 77, 1273-1281.

2. (a) Koslowski, U. I.; Abs-Wurmbach, I.; Fiechter, S.; Bogdanoff, P., Nature of the catalytic centers of porphyrin-based electrocatalysts for the ORR: a correlation of kinetic current density with the site density of $\mathrm{FeN}_{4}$ centers. J. Phys. Chem. C 2008, 112, 15356-15366; (b) Kramm, U. I.; Abs-Wurmbach, I.; Fiechter, S.; Herrmann, I.; Radnik, J.; Bogdanoff, P., New insight into the nature of catalytic activity of pyrolysed iron porphyrin based electro-catalysts for the oxygen reduction reaction (ORR) in acidic media. In Proton Exchange Membrane Fuel Cells 9, Fuller, T.; Uchida, H.; Strasser, P.; Shirvanian, P.; Lamy, C.; Hartnig, C.; Gasteiger, H. A.; Zawodzinski, T.; Jarvi, T.; Bele, P.; Ramani, V.; Cleghorn, S.; Jones, D.; Zelenay, P., Eds. 2009; Vol. 25, pp 93104; (c) Kramm, U. I.; Herrmann-Geppert, I.; Bogdanoff, P.; Fiechter, S., Effect of an ammonia treatment on structure, composition, and oxygen reduction reaction activity of $\mathrm{Fe}-\mathrm{N}-\mathrm{C}$ catalysts. J. Phys. Chem. C 2011, 115, 23417-23427.

3. Varnell, J. A.; Tse, E. C.; Schulz, C. E.; Fister, T. T.; Haasch, R. T.; Timoshenko, J.; Frenkel, A. I.; Gewirth, A. A., Identification of carbon-encapsulated iron nanoparticles as active species in non-precious metal oxygen reduction catalysts. Nat. Commun. 2016, 7, 12582. 